\title{
Oceanography
}

CITATION

Boxall, S. 2012. The oceanography classroom: Don't be too critical in thinking about our students' abilities. Oceanography 25(4):72-74, http://dx.doi.org/10.5670/oceanog.2012.109.

DOI

http://dx.doi.org/10.5670/oceanog.2012.109

COPYRIGHT

This article has been published in Oceanography, Volume 25, Number 4, a quarterly journal of The Oceanography Society. Copyright 2012 by The Oceanography Society. All rights reserved.

USAGE

Permission is granted to copy this article for use in teaching and research. Republication, systematic reproduction, or collective redistribution of any portion of this article by photocopy machine, reposting, or other means is permitted only with the approval of The Oceanography Society. Send all correspondence to: info@tos.org or The Oceanography Society, PO Box 1931, Rockville, MD 20849-1931, USA. 


\section{Don't Be Too Critical in Thinking About Our Students' Abilities}

BY SIMON BOXALL

I am not one who is easily led or swayed. I am stubborn to the point that if someone tells me to do one thing, I will probably do the opposite. A dogmatic or independent thinker? My wife would say the first. Come to think of it, so would my head of faculty. So when the editor suggested that I consider writing a column looking at how to get university students to think critically, I thoughtno, I'm not doing that. Then, I thought more critically, and realized that dogmatism (based on a priori assumption rather than empirical evidence) is the antithesis of critical thinking. Enough rhetoric. This column is, after all, about science education in oceanography and not an impalpable discursion into the English language.

The subject of this column was prompted by an article in a US newspaper that showed some alarming statistics on how students' critical thinking did not improve during their time at university. The topic was also raised at a recent meeting of The Oceanography Society Council, with similar observations, and it even came up in a discussion I had with a colleague working in the marine industry in the UK: Your students have lost the ability to think critically - what are you going to do about it? The assumption seemed to be that students once had it, but university knocked it out of them.

Some years ago, high school students in the UK began taking a formal qualification in Critical Thinking. It was introduced as a supplement to the more traditional A Levels (Advanced Levels) in subjects such as science, art, and literature. Universities didn't acknowledge this course as particularly useful, and as an admissions tutor, I would not accept it in place of, say, mathematics or chemistry. Are we wrong to still dismiss it? I would agree that students do not appear to think critically anymore.

But what is critical thinking? In Western cultures, Socrates introduced the concept as a method of hypothesis elimination through identification of theories that lead to contradictions or inconsistencies with established beliefs-sounds more like dogmatism to me when put like that. It reminds me of a statement made by my inspirational school science teacher, asserting that you can never irrefutably prove a hypothesis in science, you can only disprove it. In that sense, critical thinking is about a series of arguments that leads to a high probability of a science hypothesis being correct. But surely we thought critically before Socrates came along?

E.M. Glaser (1941) is often cited as a more contemporary authority on the subject, and makes the following vital statement: "The ability to think critically, as conceived in this volume, involves three things:

1. an attitude of being disposed to consider in a thoughtful way the problems and subjects that come within the range of one's experiences,

2. knowledge of the methods of logical inquiry and reasoning, and 3. some skill in applying those methods."

Herein we find the problem. Universities open people's minds to a wide range of possibilities in science and, for the first time, show that all that was taught in school may not be quite as it was presented, and that we don't have full answers to many questions. Not since early elementary school have our students been taught to think like this. I host many school group visits at the UK National Oceanography Centre each year, and, without fail, the critical and pertinent questions come from the seven year olds. Admittedly, the questions can be a bit off the wall, but young children are not constrained by dogma. What

Simon Boxall (srb2@noc.soton.ac.uk) is Associate Fellow, University of Southampton, National Oceanography Centre, Southampton, UK. 
then follows for these kids is 11 years of cramming facts and taking too many exams, a process that has only intensified in the present age of school rankings and accountability.

If we consider Glaser's criteria, students are getting knowledge and, I guess, with courses in critical thinking, they are also guided to think logically in their science inquiries. So why are students not thinking critically at university, where we try to break the rote learning of their school days? It is true that students have less confidence than they used to in their own ability to think. When I began teaching a few years ago, students were keen to get some idea of the structure of exams by seeing past papers, but felt confident to answer the questions based on their knowledge, understanding, and experience. Recently, I have seen a disturbing trend toward students demanding model answers-what do I have to write to get $100 \%$ ? What is the correct answer? For high school exams, there is a right answer, at least in terms of what the exam board wanted. By final year at university, there tends to be components of a right answer but often a number of ways of viewing a particular problem. As an examiner, I want to see if students can think for themselves and come up with a critical discussion of an issue, even if there are some flaws in their facts. Facts can be corrected-thinking can't.

So, returning to the questions of whether students are losing the ability to think critically and are we doing something wrong in education, I do believe students are too regimented in the way they are taught in schools and recently even at university, driven not by teacher choice but by school rankings. This doesn't help, when at university we should aim to reverse this trend. The clue for improvement is in two of Glaser's criteria: "subjects that come within the range of one's experiences" and "some skill in applying those methods.”

Thinking back, I'm not convinced I had particularly good critical thinking skills as an undergraduate. I didn't have the "experiences" that Glaser said are needed for thinking critically, and I had limited practice in applying science. Talking recently to one or two of my contemporaries who studied with me on the same courses, they agree. During my postgraduate studies I developed those experiences, aided by consistent guidance from my mentors mixed with the independence to explore. It was not so much instruction that I gained from these mentors but rather a transfer of knowledge they had gained during their years in oceanography mixed in with my own exploration (with its successes and failures). This combination taught me to think laterally and critically. It broke down dogmatism and encouraged independence. Looking at my own progress and that of my contemporaries, it is only in the past 10 years that any of us have truly thought critically well beyond even our postgrad years-but we now criticize young and inexperienced students for not thinking in a similar way.

We need to remember that it is experience that makes great scientists and engineers, along with chances to explore subjects in an open and thoughtful way. Providing the needed experiences is where universities have always had a role to play. What has changed is the time available to faculty for mentoring students, as well as a perceived need for structure throughout every hour a student spends at university. With

\section{HANDS-ON OCEANOGRAPHY}

http://www.tos.org/hands-on
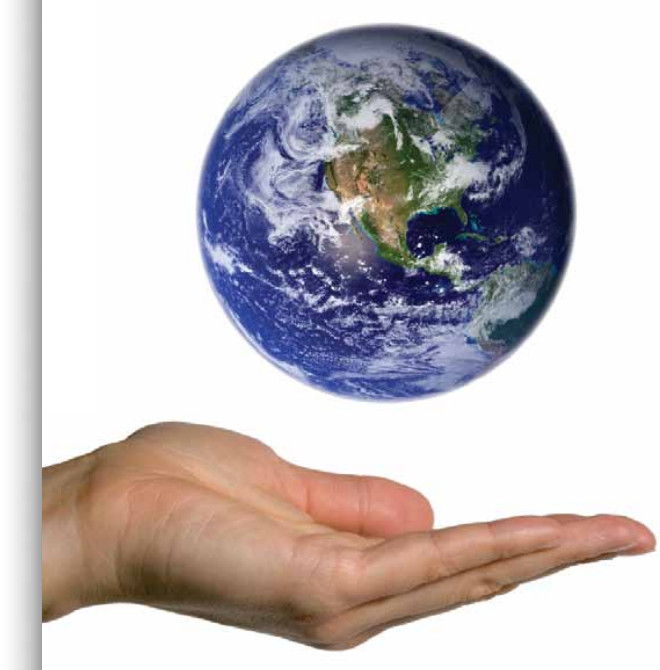

Hands-On Oceanography provides an opportunity for you to publish teaching materials developed for undergraduate and/or graduate classes in oceanography. Activities must actively engage students (i.e., activities where students have to make decisions, record results, and interpret results).

All submissions are peer reviewed. Publication of teaching materials may address the broader impacts criterion for NSF-funded research.

Visit http://www.tos.org/hands-on to download published activities or for more information on submitting an activity of your own for consideration. 
increasing numbers attending university and more demands on academic staff from nonteaching or research duties, we spend less time on average with both undergraduates and postgraduates than we did 20 years ago. More is trusted to what are often less experienced research and teaching assistants. There is less quality time spent between professor and student. Students need contact with professors to gain insight into the thought process in science. It cannot be learned; it has to be experienced.

There is a further problem. Giving a small group of students a lab or a boat and getting them to go and get some data that will support their thesis or dissertation would today be frowned upon. Health and safety issues, giving detailed instructions, providing a teaching assistant to keep an eye on things - these are essentials in the tick box of today. But if these students are completely guided,

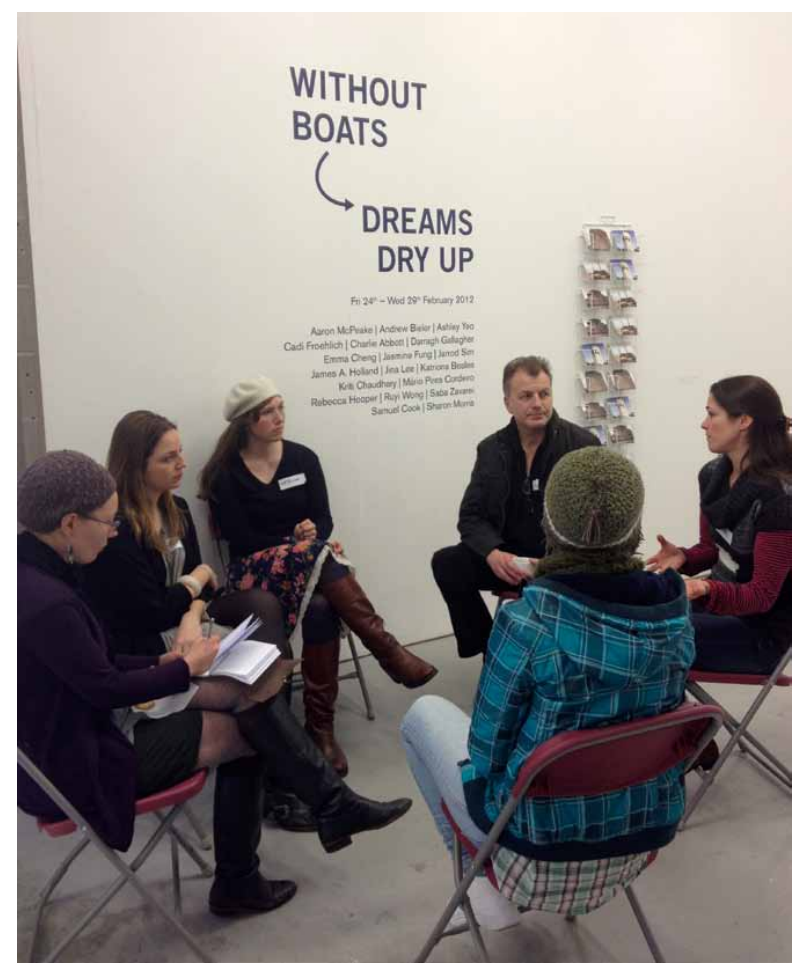

Oceanography and fine arts students share their differing views of our world at Chelsea College, London. then at what point can they begin to develop their critical thinking? When I went back to my colleague in industry to ask more about how our students have lost their ability to think critically, she qualified her response by saying that though they do follow instructions well, they don't critique and change a plan in light of evidence.

What we lack, then, is an ability to put students into new situations and let them think through the solution for themselves, with helpful hints or guidance from experienced practitioners. We do need to cover certain facts and figures in our courses; that is accepted, but perhaps we need to focus more on providing the students with experiences. They need more time with professors, not to copy but to observe and learn from them. Often, the student may well disagree with their methods or approach to a science problem, but that is good-it is the start of the process of becoming a critical thinker. It is not just research that needs critical thinkers but also commercial oceanography, to develop better and more efficient ways of getting to the core of a problem and then to its solution.

One experimental approach I recently found useful was to put a small group of oceanography students together with a group of fine art students for a weekend-very different backgrounds on the surface of it. We didn't set an agenda other than getting the group to look at differences and similarities in the two subjects. Our own students were more concerned at the start than the art students, with requests for a detailed agenda and what needed to be produced at the end. The art students went in with an open mind, with a philosophy that something interesting would emerge. It did-our students learned to think about key issues in marine science from an outsider's viewpoint. Not tied by a need to discuss fine detail, they all agreed that at the end of the short experiment, they learned to step back a bit and view the issues in a different way-to think critically-and to argue their points. This was a small step, and it could only include 10 of our 100 students, again exposing the issue of quality time, but they did see benefits, and, by their own admissions, it did help them as they approached their undergraduate dissertations.

Critical thinking is not taught, it is learned, and it can't be learned in a short time-experience is the key. Our universities need to provide opportunity and time for experience and to accept that at both undergraduate and postgraduate levels we can provide only a few, though crucial, steps to an individual developing this skill. We expect more of our new graduates than ever before, with little time for them to learn and develop on the job. Education has a role to play, and so does the employer.

\footnotetext{
REFERENCE

Glaser, E.M. 1941. An Experiment in the Development of Critical Thinking, Teacher's College, Columbia University, New York, NY, $212 \mathrm{pp}$.
} 